\title{
Physical training decreases plasma thrombomodulin in Type I and Type II diabetic patients
}

\author{
M. Rigla, J. Fontcuberta, J. Mateo, A. Caixàs, J. M.Pou, A. de Leiva, A.Pérez \\ Department of Endocrinology and Nutrition and Department of Haematology, Hospital de Sant Pau, \\ Universitat Autònoma de Barcelona
}

\section{Abstract}

Aims/hypothesis. Endothelial damage is an early step in the pathogenesis of atherosclerosis and its improvement through physical training can contribute to the known reduction of cardiovascular risk associated with exercise. An increase in some endothelium-dependent haemostatic parameters, considered as markers of endothelial damage, has been observed in diabetic patients.

Methods. The effect of a three-month physical exercise programme on thrombomodulin, tissue factor pathway inhibitor, plasminogen activator inhibitor, tissue-type plasminogen activator and von-Willebrand factor was evaluated in 14 well-controlled patients with Type I (insulin-dependent) diabetes mellitus and 13 patients with Type II (non-insulin-dependent) diabetes mellitus $\left(\mathrm{HbA}_{1 \mathrm{c}} 6.5 \pm 0.8\right.$ and $7.4 \pm 0.8 \%$, respectively). A matched control group was also studied.

Results. Thrombomodulin at baseline was higher in both Type I and Type II diabetic patients than in their respective matched control subjects $(50.0 \pm 16$ vs $31.1 \pm 8.7 \mu \mathrm{g} / 1, p<0.05 ; 51.0 \pm 10$ vs $28.5 \pm 11 \mu \mathrm{g} / \mathrm{l}$, $p<0.05$, respectively). After the exercise programme, thrombomodulin plasma concentrations had decreased $(p<0.05)$ in both groups of patients, with final thrombomodulin values being similar to those observed in their control groups $(38.2 \pm 11 \mu \mathrm{g} / \mathrm{l}$ for Type I and $34.6 \pm 12 \mu \mathrm{g} / \mathrm{l}$ for Type II patients). The thrombomodulin decrement correlated with baseline thrombomodulin and $\mathrm{VO}_{2 \max }$ increase in Type I diabetic patients. A decrease in tissue factor pathway inhibitor was also observed in Type II diabetic patients.

Conclusion/interpretation. We conclude that the normalisation of plasma thrombomodulin concentrations in Type I and Type II diabetic patients after physical training might reflect the improvement in endothelial function associated with physical exercise. [Diabetologia (2001) 44: 693-699]

Keywords Exercise, training, thrombomodulin, endothelial markers, tissue factor pathway inhibitor.
Vascular complications are the main cause of morbidity and mortality in diabetes mellitus and there is growing evidence that abnormal endothelial function is essential for the development of atherosclerosis.

Corresponding author: Dr. Antonio Pérez, Servei d'Endocrinologia i Nutrició, Hospital de Sant Pau, Avda. Sant Antoni M. Claret, 167, 08025 Barcelona, Spain

Abbreviations: TM, Thrombomodulin; TFPI, tissue-factor pathway inhibitor; vWF, von Willebrand factor; t-PA, tissue type plasminogen-activator; PAI-1, plasminogen-activator inhibitor; F $1+2$, prothrombin fragment $1+2$; TAT, thrombinantithrombin complexes; F VIIa, activated factor VII.
Endothelial cells produce several substances involved in the regulation of thrombosis and fibrinolysis [1]. The soluble forms of some of these substances, such as thrombomodulin (TM), tissue-factor pathway inhibitor (TFPI), von Willebrand factor (vWF), tissue type plasminogen-activator (t-PA) and its inhibitor, the plasminogen-activator inhibitor 1 (PAI-1), have been proposed as markers of endothelial damage. [2-5]. These markers have been found to be increased in patients with Type I (insulin-dependent) diabetes mellitus [6-8] and in patients with Type II (non-insulin-dependent) diabetes mellitus [9-11], especially in those with microvascular complications. We recently 
Table 1. Characteristics of Type I and Type II diabetic patients and control subjects at baseline and after the 3-month exercise programme

\begin{tabular}{|c|c|c|c|c|c|c|}
\hline & \multicolumn{2}{|c|}{ Type I diabetic patients } & \multirow[t]{2}{*}{ Control group } & \multicolumn{2}{|c|}{ Type II diabetic patients } & \multirow[t]{2}{*}{ Control group } \\
\hline & Baseline & After exercise & & Baseline & After exercise & \\
\hline $\begin{array}{l}\text { Number } \\
\text { of subjects }\end{array}$ & 14 & 14 & 12 & 13 & 13 & 11 \\
\hline Men/Women & $7 / 7$ & - & $6 / 6$ & $9 / 4$ & - & $7 / 4$ \\
\hline Age (years) & $25.5 \pm 6(17-42)$ & - & $27.8 \pm 6(20-42)$ & $55.8 \pm 5(48-64)$ & - & $55.4 \pm 6(43-67)$ \\
\hline $\begin{array}{l}\text { Time since } \\
\text { diagnosis }\end{array}$ & $6 \pm 5(0.7-16.2)$ & - & - & $8.2 \pm 5(2.1-19.8)$ & - & - \\
\hline $\begin{array}{l}\text { Glucose } \\
(\mathrm{mmol} / \mathrm{l})\end{array}$ & $7.9 \pm 3.6(4.1-14.4)^{\mathrm{a}}$ & $7.7 \pm 4.2(3.7-18)^{\mathrm{a}}$ & $4.7 \pm 0.4(4.3-5.7)$ & $7.9 \pm 3.3(4-13.5)^{\mathrm{a}}$ & $8.0 \pm 2.2(5.5-13)^{\mathrm{a}}$ & $5.0 \pm 0.5(4.3-5.7)$ \\
\hline $\mathrm{HbA}_{1 \mathrm{c}}(\%)$ & $6.5 \pm 0.8(5.4-8.4)^{\mathrm{a}}$ & $6.7 \pm 1(5.4-8.5)^{\mathrm{a}}$ & $5.4 \pm 0.3(5.1-5.8)$ & $7.4 \pm 0.8(5.8-8.4)^{\mathrm{a}}$ & $7.3 \pm 1(6.5-8.3)^{\mathrm{a}}$ & $5.6 \pm 0.3(5.1-6.0)$ \\
\hline $\begin{array}{l}\text { Tryglicerides } \\
(\mathrm{mmol} / \mathrm{l})\end{array}$ & $0.76 \pm 0.5(0.36-2.6)$ & $0.92 \pm 0.8(0.35-3.5)$ & $0.88 \pm 0.2(0.55-1.3)$ & $1.46 \pm 0.5(0.55-2.16)$ & $1.32 \pm 0.7(0.45-2.1)$ & $1.4 \pm 0.6(0.4-1.8)$ \\
\hline
\end{tabular}

${ }^{\mathrm{a}} p$ value $<0.05$ compared with control group; ${ }^{\mathrm{b}} p$ value $<0.05$ compared with baseline

showed that glycaemic control optimisation normalises TFPI but not TM plasma concentrations in Type I diabetic patients without chronic complications [12]. In addition to its beneficial effect on classical risk factors for vascular disease [13-15], improvement in coronary artery endothelial function could be involved in the reduction of cardiovascular risk associated with exercise [16]. No data are, however, available on the effect of physical exercise training, a widely-recommended lifestyle intervention for managing diabetes [17], on markers of endothelial damage in diabetic patients. The purpose of this study was to determine the influence of a three-month physical exercise programme on plasma markers of endothelial damage involved in haemostasis, in Type I and Type II diabetic patients.

\section{Subjects and methods}

Subjects. The study group comprised thirty diabetic patients (15 Type I and 15 Type II) and 23 healthy control subjects matched for sex, age and body mass index (BMI). All patients were selected from our diabetic outpatient clinic and met the following criteria: a BMI of less than $30 \mathrm{~kg} / \mathrm{m}^{2}, \mathrm{HbA}_{1 \mathrm{c}}$ less than $8.5 \%$, absence of kidney failure, liver or thyroid disease and a lack of regular exercise. A woman with Type I diabetes and two Type II diabetic men were excluded because of an episode of acute hepatitis $\mathrm{A}$ and inadequate compliance with the exercise programme, respectively.

The main characteristics of the 27 eligible patients and the control subjects are shown in Table 1. The four Type II diabetic women included were postmenopausal but none used hormonal replacement therapy. During the study period no patient was allowed to take any drug known to influence lipid concentrations, apart from insulin. All were treated with diet and insulin except for two Type II diabetic patients who were treated only with diet therapy. All the patients had been attending our outpatient clinic for at least one year prior to the study and had been instructed in diabetes care (diet, blood glucose monitoring, insulin administration and self-adjustment, etc). Body weight and glycaemic control were stable in all. Ten patients were smokers and six were consumers of alcoholic drinks $(<200 \mathrm{~g} /$ week $)$.

No Type I diabetic patient suffered from clinical diabetesrelated complications and among the Type II diabetic patients, two had background retinopathy and two microalbuminuria. Diabetes-related complications were screened by history, physical examination, retinal fundoscopy, repeated measurements of albumin excretion rate and $128-\mathrm{Hz}$ tuning fork. No patients had a history or clinical manifestations of peripheral vascular disease or stroke. The only hypertensive patient had suffered an acute myocardial infarction two years earlier and was treated with the same dose of acetylsalicylic acid $(100 \mathrm{mg})$ throughout the study period.

Study protocol. The training programme lasted three months and was held at the same fitness centre for all study participants. Attendance at the centre was recorded on a personal chipcard. Patients were instructed to attend the fitness centre at least three times a week and not to modify their other usual daily activities. An individualised aerobic exercise programme was designed according to the patients' characteristics and the degree of their physical fitness, which was determined by means of a treadmill exercise test carried out at the beginning of the study and repeated after three months of training. All exercise sessions were supervised by a coach specifically trained by the investigators. Each session included $10 \mathrm{~min}$ of warm-up, 30 to $40 \mathrm{~min}$ of aerobic activity and $10 \mathrm{~min}$ of cooldown. The exercise consisted mainly of walking or running on a treadmill, cycling, or a combination of both. Initially, subjects exercised at an intensity corresponding to 60 to $65 \%$ maximal oxygen consumption $\left(\mathrm{VO}_{2 \max }\right)(1-2$ weeks) and 65 to $75 \%$ $\mathrm{VO}_{2 \max }$ thereafter to improve their aerobic capacity. Intensity of each session was monitored by heart rate. The exercises and the intensity and duration of each training session were recorded in an individual logbook to determine the energy expenditure as Kcal per week, using a method proposed by others [18].The exercise test was carried out as described elsewhere [15].

Patients were taught how to modify their insulin dose or diet to avoid exercise-related hypoglycaemia and instructed 
Table 2. Anthropometric data, physical fitness, and lipoprotein concentrations at baseline and after 3 months of an exercise programme in Type I and Type II diabetic patients. BMI; body mass index; $\mathrm{VO}_{2 \max }$; maximal oxygen consumption

\begin{tabular}{|c|c|c|c|c|}
\hline & \multicolumn{2}{|c|}{ Type I diabetic patients } & \multicolumn{2}{|c|}{ Type II diabetic patients } \\
\hline & Baseline & After exercise & Baseline & After exercise \\
\hline $\mathrm{BMI}(\mathrm{kg} / \mathrm{m} 2)$ & $23.8 \pm 3$ & $23.8 \pm 3$ & $26.6 \pm 3.6$ & $26.3 \pm 3.6$ \\
\hline Waist $(\mathrm{cm})$ & $75.6 \pm 8$ & $74.1 \pm 7$ & $91.4 \pm 9$ & $89.4 \pm 9$ \\
\hline Hip $(\mathrm{cm})$ & $97.8 \pm 7$ & $95.5 \pm 5$ & $101.7 \pm 6$ & $98.5 \pm 7$ \\
\hline Waist/Hip & $0.77 \pm 0.6$ & $0.77 \pm 0.4$ & $0.89 \pm 0.5$ & $0.90 \pm 0.4$ \\
\hline Systolic BP (mmHg) & $116 \pm 9,2$ & $117 \pm 9$ & $127 \pm 8,7$ & $123 \pm 9$ \\
\hline Diastolic BP (mmHg) & $69.4 \pm 4,4$ & $69.5 \pm 5$ & $80.2 \pm 10$ & $73.8 \pm 5^{\mathrm{a}}$ \\
\hline Maximal treadmill time (min) & $13.5 \pm 2.2$ & $14.0 \pm 2$ & $10.4 \pm 1.2$ & $11.4 \pm 13^{\mathrm{a}}$ \\
\hline LDL-cholesterol (mmol/l) & $2.70 \pm 0.74$ & $2.56 \pm 0.65$ & $3.65 \pm 1.0$ & $3.40 \pm 0.87^{b}$ \\
\hline HDL-cholesterol (mmol/l) & $1.48 \pm 0.45$ & $1.66 \pm 0.66^{\mathrm{a}}$ & $1.26 \pm 0.37$ & $1.23 \pm 0.39$ \\
\hline VLDL-cholesterol (mmol/l) & $0.35 \pm 0.27$ & $0.33 \pm 0.15$ & $0.66 \pm 0.26$ & $0.60 \pm 0.31$ \\
\hline
\end{tabular}

${ }^{\mathrm{a}} p$ value $<0.05$ compared with baseline; ${ }^{\mathrm{b}} p$ value $<0.01$ compared with baseline

to monitor their blood glucose three or more times a day. All were seen in the outpatient unit every four weeks to reinforce their compliance with the programme and were instructed in insulin dose modification. Aerobic capacity, anthropometric parameters and laboratory analyses were evaluated before and after the planned exercise programme.

Height and weight were measured with the patient in light clothing without shoes on a standard physician's scale, and body mass index (BMI) was calculated. Waist and hip perimeters were measured and waist-to-hip ratio was (WHR) calculated. Waist circumference was taken as the smallest horizontal circumference between the $12^{\text {th }}$ rib and the iliac crest and hip circumference as the maximum posterior extension of the buttocks.

Twenty-four-hour ambulatory blood pressure was registered using a Spacelab 90207 device (Redmon, Wash., USA). During the estimated waking hours (700 to 2300 hours), blood pressure was recorded every $20 \mathrm{~min}$, and every $30 \mathrm{~min}$ during the overnight period.

Laboratory analysis. Blood samples were obtained with the patient seated and after at least a 10-h overnight fast and after a minimum of $24 \mathrm{~h}$ from the last exercise session. Glucose, $\mathrm{HbA}_{1 \mathrm{c}}$, cholesterol, triglyceride and cholesterol fractions were measured as described previously [15].

Blood samples to determine coagulation parameters were collected in evacuated tubes containing $0.129 \mathrm{~mol} / \mathrm{l}$ trisodium citrate. Platelet-poor plasma was harvested by centrifugation at $1600 \mathrm{~g}$ for $20 \mathrm{~min}$ and stored at $-40^{\circ} \mathrm{C}$ until analysis. Thrombomodulin was measured by an immunoenzymatic assay (Asserachrom Thrombomodulin, Boehringer-Mannheim, Mannheim, Germany; Intra-assay coefficient of variation less than $8 \%$ and inter-assay coefficient of variation less than $10 \%$ ) [19]. Functional tissue factor pathway inhibitor was assayed as described elsewhere [20]. Activated factor VII was also measured (Staclot VIIa-rTF, Stago, Asnières, France). Antigenic von Willebrand factor was measured by ELISA (anti-human von Willebrand factor, Dako, Denmark). Tissue-type plasminogen activator was measured by ELISA (Asserachrom t-PA, Boehringer-Mannheim, Mannheim, Germany). Functional plasminogen activator inhibitor was also measured (PAI-Chromogen, Boehringer-Mannheim, Mannheim, Germany).

The following measurements were also done: prothrombin fragment $1+2(\mathrm{~F} 1+2)$ (Enzygnost $\mathrm{F} 1+2$ micro, Behring, Marburg, Germany), thrombin-antithrombin complexes (TAT) (Enzygnost TAT micro, Behring, Marburg, Germany) and D-Dimer (Asserachrom D-Dimer, Boehringer-Mannheim, Mannheim, Germany).

Statistical methods. Statistical analyses were done using the computer software package SPSS for Windows (8.0; SPSS Inc, Chicago, Ill., USA) program. Data were expressed as means \pm SD. All tests were two-tailed and a probability of less than 0.05 was considered to be statistically significant. Normality of distribution of any variable was assessed with the Kolmogorov-Smirnov test. Comparisons between the diabetic patients and their respective control groups were done using unpaired Student's $t$ test and Mann-Whitney U test. Statistical differences between the two periods (pre-exercise and post-exercise) were analysed by a non-parametric test (Wilcoxon ttest) for variables showing non-normal distribution, and paired Student's $t$ test was used for normally distributed variables. One-way analysis of variance (ANOVA) was applied for between-group comparison. Spearman rank-order correlation was used to examine the relation between non-normally-distributed variables. Pearson's correlation coefficient was applied to assess the relation between normally-distributed variables.

\section{Results}

Physical activity, anthropometric data and fitness. Average attendance at the sports centre was $3.1 \pm 0.8$ days per week. Mean caloric expenditure per week derived from exercise was $30.1 \pm 4.7 \mathrm{kcal} /$ $\mathrm{kg}$ per week for Type I and $24.1 \pm 6.3 \mathrm{kcal} / \mathrm{kg}$ per week for Type II diabetic patients. Anthropometric characteristics before and after the exercise programme are shown in Table 2. Improvements in $\mathrm{VO}_{2 \max } \quad(33.7 \pm 7.0$ vs $38.5 \pm 7.7 \mathrm{ml} / \mathrm{kg}$ a min, $p<0.05)$ and $\mathrm{O}_{2}$ pulse $(12.2 \pm 2.8$ vs $13.4 \pm 3.7 \mathrm{ml} /$ beat, $p<0.05)$ were observed after physical training in Type I diabetic patients. In Type II patients only maximal treadmill time improved significantly $(10.4 \pm 1.2$ vs $11.4 \pm 2.3 \min , p<0.05)$.

Glycaemic control, lipid and lipoprotein parameters. $\mathrm{HbA}_{1 \mathrm{c}}$ and fasting blood glucose did not change dur- 
Table 3. Haemostatic markers of control subjects and Type I diabetic patients at baseline and after the 3-month exercise programme. Data are shown as means \pm SD or as median (range) for skewed data. Soluble thrombomodulin (TM), Functional Tissue Factor Pathway Inhibitor (TFPI), antigenic von Willebrand factor (vWF), tissue factor (TF), activated Factor VII (F VII $)_{\mathrm{a}}$, tissue-type plasminogen activator (t-PA), functional plasminogen activator inhibitor (PAI-1), prothrombin fragment $1+2(\mathrm{~F} 1+2)$, thrombin-antithrombin complexes (TAT)

\begin{tabular}{|c|c|c|c|}
\hline & \multicolumn{2}{|c|}{ Type I diabetic patients } & \multirow[t]{2}{*}{ Control Group } \\
\hline & Baseline & After exercise & \\
\hline $\mathrm{TM}(\mu \mathrm{g} / \mathrm{l})$ & $51.0 \pm 10^{\mathrm{a}}$ & $34.6 \pm 12^{\mathrm{b}}$ & $28.5 \pm 11$ \\
\hline TFPI (\%) & $107.0 \pm 49$ & $107.1 \pm 26$ & $91.5 \pm 25$ \\
\hline vWF (\%) & $105 \pm 29$ & $118.2 \pm 47$ & $142 \pm 74$ \\
\hline $\mathrm{FVII}_{\mathrm{a}}(\mathrm{U} / \mathrm{L})$ & $64.1 \pm 18.6$ & $58.2 \pm 14.9$ & $56.4 \pm 12.9$ \\
\hline $\mathrm{TF}(\mathrm{ng} / \mathrm{l})$ & $108(80-504)$ & $138(22-332)$ & 157 (114-199) \\
\hline $\mathrm{t}-\mathrm{PA}(\mu \mathrm{g} / \mathrm{l})$ & $3.98 \pm 2.4$ & $2.9 \pm 1.4$ & $4.39 \pm 2.1$ \\
\hline $\begin{array}{l}\mathrm{PAI}-1 \\
(\mathrm{AU} / \mathrm{ml})\end{array}$ & $7.46 \pm 8.3$ & $9.7 \pm 8.7^{\mathrm{b}}$ & $6.96 \pm 5.14$ \\
\hline Fibrinogen & $2.89 \pm 0.5$ & $2.85 \pm 0.4$ & $3.05 \pm 0.76$ \\
\hline $\begin{array}{l}\mathrm{F} 1+2 \\
(\mathrm{nmol} / \mathrm{l})\end{array}$ & $0.82(0.64-1.1)$ & $0.92(0.75-2.58)^{\mathrm{b}}$ & $1.01(0.65-1.14)$ \\
\hline $\begin{array}{l}\text { D-Dimer } \\
(\mu \mathrm{g} / \mathrm{l})\end{array}$ & $246(204-327)$ & 333 (209-936) & $186(167-682)$ \\
\hline TAT $(\mu \mathrm{g} / \mathrm{l})$ & $4.32(1.99-10.8)$ & $7.31(0.99-84)$ & $6.6(3.73-160)$ \\
\hline
\end{tabular}

${ }^{\mathrm{a}} p$ value $<0.05$ compared with control group; ${ }^{\mathrm{b}} p$ value $<0.05$ compared with baseline

Table 4. Haemostatic markers of control subjects and Type II diabetic patients at baseline and after the 3-month exercise programme. Data are shown as means \pm SD or as median (range) for skewed data. Soluble thrombomodulin (TM), Functional Tissue Factor Pathway Inhibitor (TFPI), antigenic von Willebrand factor (vWF), tissue factor (TF), activated Factor VII (F $\mathrm{VII}_{\mathrm{a}}$ ), tissue-type plasminogen activator (t-PA), functional plasminogen activator inhibitor (PAI-1), prothrombin fragment $1+2(\mathrm{~F} 1+2)$, thrombin-antithrombin complexes (TAT)

\begin{tabular}{lccc}
\hline & \multicolumn{2}{c}{ Type II diabetic patients } & Control group \\
\cline { 2 - 3 } & Baseline & After exercise & \\
\hline TM $(\mu \mathrm{g} / \mathrm{l})$ & $50.0 \pm 16^{\mathrm{a}}$ & $38.2 \pm 11^{\mathrm{b}}$ & $31.1 \pm 8$ \\
TFPI $(\%)$ & $133.7 \pm 33^{\mathrm{a}}$ & $97.7 \pm 20^{\mathrm{b}}$ & $124.7 \pm 47$ \\
vWF $(\%)$ & $184.5 \pm 98$ & $153.3 \pm 61$ & $154.2 \pm 80$ \\
F VIIa U/L & $60.2(16.7-140.6)^{\mathrm{a}}$ & $73.7(15.7-106.8)$ & $94.5(70.4-221.8)$ \\
TF $(\mathrm{ng} / \mathrm{l})$ & $184 \pm 77$ & $228 \pm 144$ & $206.1 \pm 28$ \\
t - PA $(\mu \mathrm{g} / \mathrm{l})$ & $7.13 \pm 2.3$ & $7.6 \pm 2.5$ & $8.8 \pm 4$ \\
PAI 1 1 $(\mathrm{AU} / \mathrm{ml})$ & $14.7 \pm 11$ & $17.3 \pm 9.6$ & $19.8 \pm 14$ \\
Fibrinogen & $3.54 \pm 0.8$ & $3.63 \pm 0.8$ & $3.26 \pm 0.7$ \\
F 1 + 2 (nmol/l) & $1.17(0.8-2.88)^{\mathrm{a}}$ & $1.09(0.8-5.46)$ & $2.15(0.67-5.78)$ \\
D-Dimer $(\mu \mathrm{g} / \mathrm{l})$ & $324.5(102-1915)$ & $305(114-864)$ & $285(184-332)$ \\
TAT $(\mu \mathrm{g} / \mathrm{l})$ & $5.54(2.02-86)$ & $5.18(2.22-62.2)$ & $6.02(5.37-10.9)$ \\
\hline
\end{tabular}

${ }^{\mathrm{a}} p$ value $<0.05$ compared with control group; ${ }^{\mathrm{b}} p$ value $<0.05$ compared with baseline

ing the training period in both diabetic groups (Table 1). Insulin dose decreased $(0.40 \pm 0.18$ vs $0.31 \pm 0.19 \mathrm{U} / \mathrm{kg}$ a day, $p<0.05)$ in Type II but remained stable in Type I diabetic patients. No patients suffered any severe hypoglycaemic event.



Fig. 1. Individual changes observed in absolute values of plasma thrombomodulin between both periods of study (baseline and after a 3-month physical exercise program) in a group of Type I and Type II diabetic patients

Lipid and lipoprotein concentrations in Type I and Type II diabetic patients before and after physical training are shown in Tables 1 and 2. HDL-c increased in Type I diabetic patients (percentage of change: $10.7 \pm 17.3 \%, p<0.05)$ and LDL-c concentrations decreased (percentage of change: $7.47 \pm$ $7.2 \%, p<0.01)$ in Type II diabetic patients.

Endothelial markers and coagulation activation indicators. Haemostatic markers of control subjects and diabetic patients are shown in Tables 3 and 4.

Before starting the physical training, Type I and Type II diabetic patients showed higher TM concentrations than the control subjects. Furthermore, TFPI activity was also higher in Type II patients than in their respective control group. After the exercise programme, TM decreased significantly in both groups of patients (Fig.1), with mean postexercise TM concentrations being similar to TM observed in the control group. In Type I diabetic patients, decrements in TM concentrations correlated with baseline TM concentrations $(\mathrm{R}=0.54 ; p=0.047)$ and with the observed change in $\mathrm{VO}_{2 \text { max }}(\mathrm{R}=0.65 ; p=0.017)$. Furthermore, TFPI decreased and vWF tended to decrease $(p=0.07)$ in Type II diabetic patients. PAI-1 also increased significantly in Type I diabetic patients but both pre-exercise and post-exercise values did not differ from those observed in the control group. FVIIa were lower in the Type II diabetic group at baseline but post-exercise concentrations did not differ from the control group. No significant changes in $\mathrm{TF}$ and fibrinogen were observed. Baseline F1 + 2 concentrations of coagulation activation products, were lower in Type II diabetic patients than in their control group and, in Type I diabetic patients, increased significantly after exercise. However, TAT and D-Dimer did not change (Table 3). After excluding the hypertensive patient who had suffered a myocardial infarction the main results (changes in TM, TFPI, vWF, F1 + 2, etc.) did not change. 


\section{Discussion}

Our study examined the effect of physical training on endothelial function markers related to haemostasis in diabetic subjects. We showed that, in addition to improving other metabolic abnormalities [15], physical training normalised high plasma thrombomodulin concentrations in a group of patients whose Type I and Type II diabetes was well-controlled. Furthermore, physical training reduced the high TFPI activity observed in Type II diabetic patients.

Despite the small number of patients included in this study, the lack of comparison with a diabetic group that did not exercise and the absence of direct data on endothelial function, these findings are of interest. Firstly, the study design minimises the influence of interindividual factors on TM changes; secondly, the results are coincident for both Type I and Type II diabetic patients and baseline values are similar to those obtained previously by our group in newly-diagnosed Type I diabetic patients [12]; thirdly, soluble TM has been stated as a marker of endothelial damage [2]. Finally, improved endothelial function derived from physical training has been proposed to explain in part the beneficial effect of exercise to minimize cardiovascular risk [16].

Diabetic patients, both Type I and Type II, show various coagulation and fibrinolytic abnormalities related to vascular endothelial dysfunction. These alterations have been observed particularly in patients with clinical features derived from microangiopathy [21-29], and also in patients free of complications [30] and include increased plasma concentrations of some products involved in thrombosis phenomena produced, at least in part, in the vascular endothelium. Thrombomodulin seems to be one of the most specific markers of endothelial injury, because it is not constitutively secreted from the cells but results from endothelial damage [31] and, in contrast to other endothelial markers, does not appear to be associated with factors such as BMI, WHR, age or lipids. [32]. Moreover, TM is increased in a variety of diseases that produce vascular injury [33], including Type I [21-24] and Type II [9, 25-29] diabetes and is not related to glycaemic control [12]. In accordance with these data, diabetic patients included in our study showed increased TM concentrations at baseline. The main finding of this study was, however, related to the normalisation of TM concentrations in both Type I and Type II diabetic patients after exercise training.

Recent works support the hypothesis that physical training improves endothelial function, particularly in patients with high cardiovascular risk [16, 34-37]. The mechanisms responsible for these beneficial effects have been studied in experimental models. There is growing understanding that as a consequence of the increased vascular shear stress derived from repetitive exercise, endothelial cells respond by increasing their production of nitric oxide and other vasodilatory products [38]. As soluble TM is an accepted marker of endothelial damage, the restoration of normal TM values observed in our study after a physical training programme might mirror the improvement in endothelial function derived from exercise. Despite much interest in soluble TM as a marker for endothelial injury, no data are available which focused on the the effect of training on TM concentration. An acute and prolonged bout of exercise (running, but not swimming or cycling) has been shown to increase soluble TM concentrations [39]. However, the acute effect of intense exercise could differ from the adaptative response of endothelium to a regular exercise programme, as for other coagulation parameters.

To our knowledge, no study has answered the question of whether TM reduction reflects improvement in endothelial function. However, some indirect evidence exists. Pharmacological vasodilation through cilostazol has been associated with a decrease in TM concentrations in Type II diabetic patients [40] and treatment with the angiotensin-converting enzyme inhibitor enalaprilat, with a known protective effect on endothelium, reduced the release of TM and other soluble endothelial-derived substances in critically-ill patients [40]. These findings support the hypothesis that the reduction in TM concentrations observed in our study after the exercise programme could reflect an improvement in endothelial function.

Regarding our group of Type II diabetic patients, a decrease in TFPI concentrations and a tendency towards diminished vWF plasma was also observed, thereby reinforcing the possible protective effect of exercise on endothelium. The reduction in plasma vWF concentrations in Type II diabetic patients after the exercise programme concurs with findings of previous studies [42]. The lack of changes in the other markers could be due to the more favourable concentrations at baseline, particularly in Type I diabetic patients and also a consequence of the small sample studied.

After training, the lower F1 + 2 concentrations observed in Type II diabetic patients normalised and in Type I diabetic patients baseline values increased. Although no correlation was found between TM and F $1+2$ concentrations or between changes observed in both parameters after physical training, an influence of TM variations on F $1+2$ values could be expected. Circulating TM might not only reflect endothelial damage, but also exert an anticoagulant effect as part of protection against injury. Recently, both TM and TFPI have been proposed as anticoagulant therapy, although studies are in the preclinical phase [43]. Nevertheless, F $1+2$ values in both Type I and Type II diabetic patients post-exercise did not differ from 
those observed in their respective control groups; thus, the F $1+2$ increase does not seem to represent a putative adverse effect of exercise.

Activated factor VII in Type II diabetic patients was lower than in the control group at baseline but similar after exercise. An FVII increase after training has been reported in a population-based study [44] but only in the group undertaking strenuous exercise. As the intensity of the exercise performed was low, we speculate that the mild increase found in FVIIa observed might be related to the decrease observed in TFPI.

It has been described that training decreases PAI-1 $[45,46]$, probably by improving insulin sensitivity [47]. However, the opposite has also been described [48]. In our group of Type I diabetic patients, PAI-1 concentrations significantly increased after physical training but neither the pre-exercise nor the post-exercise values differed from the mean concentrations observed in the control group. Thus, this finding does not seem to be biologically important.

The effects of physical training on the coagulation system have been insufficiently studied. Acute exercise produces an increase in factor VIII coagulant activity [47] whereas prolonged endurance exercise has not proved to alter this activity [48]. Furthermore, training prevents the post-exercise increase in fibrinogen [45]. Acute exercise above $50 \%$ of maximal workload significantly increases fibrinolytic activity by releasing tPA from endothelium [49]. Controversy exists regarding the effect of training on the fibrinolytic system in Type I and Type II diabetic patients $[44,50]$.

In summary, Type I and Type II diabetic patients showed increased soluble TM concentrations. After 3 months of a supervised training programme, TM decreased in both groups and became similar to the concentrations observed in their respective control subjects. The magnitude of the TM reduction correlated with $\mathrm{VO}_{2 \max }$ variation in Type I diabetic patients. In accordance with the results of our study we conclude that increased soluble TM concentrations could reflect endothelial damage in well-controlled diabetic patients and that the normalisation of TM concentrations after physical exercise could mirror the physical training-related improvement in endothelial function.

Acknowledgements. We are indebted to J. Úbeda, T. Urrutia and R. Felices for their educational support to the patients and for their helpful technical assistance. We are also indebted to Miss C. O'Hara for English language revision of the manuscript and to the Sport Centre DiR for its collaboration.

\section{References}

1. Stern DM, Esposito C, Gerlach H et al. (1991) Endothelium and regulation of coagulation. Diabetes Care 14 [Suppl 1]: $160-166$

2. Seigneur M, Dufourc P, Conri C et al. (1993) Levels of plasma thrombomodulin are increased in atheromatous arterial disease. Thromb Res 71: 423-431

3. Sandset PM, Sirnes PA, Abildgaard U (1989) Factor VII and extrinsic pathway inhibitor in acute coronary disease. Br J Haemat 72: 391-396

4. Boneu B, Abbal M, Plante J, Bierme R (1975) Factor VIII complex and endothelial damage. Lancet i (7922): 1430

5. Dawson S, Henney A (1992) The status of PAI-1 as a risk factor for arterial and thrombotic disease : a review. Atherosclerosis 95: 105-117

6. Stehouwer CDA, Stroes ESG, Hackeng WHL, Mulder PGH, Den Ottolander GJH (1991) Von Willebrand factor and development of diabetic nephropathy in IDDM. Diabetes 40: 971-976

7. Carmassi F, Morale M, Puccetti R et al. (1992) Coagulation and fibrinolytic system impairment in insulin-dependent diabetes mellitus. Thromb Res 67: 643-654

8. Iwashima Y, Sato T, Watanabe K et al. (1990) Elevation of plasma thrombomodulin level in diabetic patients with early diabetic nephropathy. Diabetes 39: 983-988

9. Sumida Y, Wada H, Fujii M et al. (1997) Increased soluble fibrin monomer and soluble thrombomodulin levels in non-insulin-dependent diabetes mellitus. Blood Coagul Fibrinolysis 8: 303-307

10. Kario K, Matsuo T, Kobayashi H, Matsuo M, Sakata T, Miyata T (1995) Activation of tissue factor-induced coagulation and endothelial cell dysfunction in non-insulin-dependent diabetic patients with microalbuminuria. Arterioscler Thromb Vasc Biol 15: 1114-1120

11. Knöbl P, Schernthaner G, Schnack C et al. (1993) Thrombogenic factors are related to urinary albumin excretion rate in Type I (insulin-dependent) and Type II (non-insulin-dependent) diabetic patients. Diabetologia 36: 1045-1050

12. Rigla M, Mateo J, Fontcuberta J, Souto JC, de Leiva A, Pérez A (2000) Normalisation of tissue factor pathway inhibitor activity after glycaemic control optimisation in type 1 diabetic patients. Thromb Haemost 84: 223-227

13. Hellsten G, Bomank K, Hallmans G et al. (1989) Lipids and endurance physical activity. Atherosclerosis 75: 93-94

14. Austin A, Warty V, Janosky J et al. (1993) The relationship of physical fitness to lipid and lipoprotein (a) levels in adolescents with IDDM. Diabetes Care 16: 421-425

15. Rigla M, Sánchez-Quesada JL, Ordóñez-Llanos J et al. (2000) Effect of physical exercise on lipoprotein (a) and LDL modifications in type 1 and type 2 diabetic patients. Metabolism 49: 640-647

16. Hambrecht R, Wolf A, Gielen S et al. (2000) Effect of exercise on coronary endothelial function in patients with coronary artery disease. New Engl J Med 342: 454-460

17. American Diabetes Association (2000) Diabetes Mellitus and exercise Diabetes Care 23 [Suppl 1]: S50-S54

18. Ainswoth BE, Haskell WL, Leon AS et al. (1993) Compendium of physical activities: classification of energy cost of human physical activities. Med Sci Sports Exerc 1: 71-80

19. Amiral J, Adam M, Mimilla F, Larrivaz I, Chambrette B, Boffa MC (1994) Design and validation of a new immunoassay for soluble forms of thrombomodulin and studies on plasma. Hybridoma 13: 205-209

20. Sandset PM, Abildgaard U, Pettersen M (1987) A sensitive assay of extrinsic coagulation pathway inhibitor in plasma and plasma fractions. Thromb Res 47: 389-400 
21. Reverter JL, Reverter JC, Tàssies D et al. (1997) Thrombomodulin and induced tissue factor expression on monocytes as markers of diabetic microangiopathy: A prospective study on hemostasis and lipoproteins in insulin-dependent diabetes mellitus. Am J Hematol 56: 93-99

22. Leurs PB, van Oerle R, Wolffenbuttel BHR, Hamulyak K (1997) Increased tissue factor pathway inhibitor (TFPI) and coagulation in patients with insulin-dependent diabetes mellitus. Thromb Haemost 77: 472-476

23. Gruden G, Pagano G, Romagnoli R, Frezet D, Olivetti C, Cavallo-Perin P (1995) Thrombomodulin levels in insulindependent diabetic patients with microalbuminuria. Diabet Med 12: 258-260

24. Hoffman MA, Kohl B, Zumbach MS et al. (1998) Hyperhomocyst(e)inemia and endothelial dysfunction in IDDM. Diabetes Care 21: 841-848

25. Tanaka A, Ishii H, Hiraishi S, Kazama M, Maezawa H (1991) Increased thrombomodulin values in plasma of diabetic men with microangiopathy. Clin Chem 37: 269-272

26. Oida K, Takai H, Maeda H et al. (1990) Plasma thrombomodulin concentration in diabetes mellitus. Diabetes Res Clin Pract 10: 193-196

27. Gabazza EC, Takeya H, Deguchi H et al. (1996) Protein C activation in NIDDM patients. Diabetologia 39: 1455-1461

28. Inukai T, Fujiwara Y, Tayama K, Aso Y, Takemura Y (1996) Clinical significance of urinary and serum thrombomodulins in patients with non-insulin-dependent diabetes mellitus. Diabetes Res Clin Pract 33: 99-104

29. Shimano H, Takahashi K, Kawakami M et al. (1994) Elevated serum and urinary thrombomodulin levels in patients with non-insulin-dependent diabetes mellitus. Clin Chim Acta 225: 89-96

30. Aso Y, Inukai T, Takemura Y (1998) Mechanisms of elevation of serum and urinary concentrations of soluble thrombomodulin in diabetic patients: possible applications as a marker for vascular endothelial injury. Metabolism 47: 362-365

31. Ishii H, Uchiyama H, Kazama M (1991) Soluble thrombomudulin antigen in conditioned medium is increased by damage of endothelial cells. Thromb Haemost 65: 618-623

32. Nilson TK, Hellsten G, Amiral J (1993) Plasma thrombomodulin concentrations in relation to cardiovascular risk factors in a population sample. Blood Coagul Fibrinolysis 4: $455-458$

33. Takahashi H, Ito S, Hanano M et al. (1992) Circulating thrombomodulin as a novel endothelial cell marker: comparison of its behavior with von Willebrand factor and tissue-type plasminogen activator. Am J Hematol 41: 32-39

34. Lewis TV, Dart AM, Chin-Dusting JP, Kingwell BA (1999) Exercise training increases basal nitric oxide production from the forearm in hypercholesterolemic patients. Arterioscler Thromb Vasc Biol 19: 2782-2787

35. Higashi Y, Sasaki S, Kurisu S et al. (1999) Regular aerobic exercise augments endothelium-dependent vascular relaxation in normotensive as well as hypertensive subjects: role of the endothelium-derived nitric oxide. Circulation 100: $1194-1202$

36. Lavrencic A, Salobir BG, Keber I (2000) Physical training improves flow-mediated dilation in patients with the poly- metabolic syndrome. Arterioscler Thromb Vasc Biol 20: 551-555

37. Hambrecht R, Hillbrich L, Erbs S et al. (2000) Correction of endothelial dysfunction in chronic heart failure: additional effects of exercise training and oral L-arginine supplementation. J Am Coll Cardiol 35: 706-713

38. Niebauer J, Cooke JP (1996) Cardiovascular effects of exercise: role of endothelial shear stress. J Am Coll Cardiol 28: $1652-1660$

39. Weiss C, Welsch B, Albert M et al. (1998) Coagulation and thrombomodulin in response to exercise of different type and duration. Med Sci Sports Exerc 30: 1205-1210

40. Tani N, Hada K, Kitami A et al. (1993) Effects of salicylic acid and cilostazol administration on serum thrombomodulin concentration in diabetic patients. Thromb Res 69: 153-158

41. Boldt J, Papsdorf M, Kumle B, Piper S, Hempelmann G (1998) Influence of angiotensin-converting enzyme inhibitor enalaprilat on endothelial-derived substances in the critically ill. Crit Care Med 26: 1663-1670

42. Yarnell JW, Sweetnam PM, Rumley A, Lowe GD (2000) Lifestyle and hemostatic risk factors for ischemic heart disease: the Caerphilly Study. Arterioscler Thromb Vasc Biol 20: 271-279

43. Hirsh J (1999) New antithrombotic agents. Lancet 353: 1431-1436

44. Connelly JB, Cooper JA, Meade TW (1992) Strenuous exercise, plasma fibrinogen and factor VII activity. Br Heart J 6: 351-354

45. Van den Burg PJM, Dooigewaard G, Van Vliet M, Mosterd WL, Kluft C, Huisveld IA (1997) Effect of endurance training and seasonal fluctuation on coagulation and fibrinolysis in young sedentary men. J Appl Physiol 82: 613-620

46. Schneider SH, Kim HC, Khachadurian AK, Ruderman NB (1988) Impaired fibrinolytic response to exercise in type II diabetes: effects of exercise and physical training. Metabolism 37: 924-929

47. Stratton JR, Chandler WL, Schwartz RS et al. (1991) Effects of physical conditioning on fibrinolytic variables and fibrinogen in young and old adults. Circulation 83: 1692-1697

48. Estelles A, Aznar J, Tormo G, Sapena P, Tormo V, España F (1989) Influence of a rehabilitation sports programme on the fibrinolytic activity of patients after myocardial infarction. Thromb Res 55: 203-212

49. Iatridis SG, Ferguson J H (1963) Effect of physical exercise on blood clotting and fibrinolysis. J Appl Physiol 18: 337-344

50. Ponjee GAE, Janssen GME, Wersch WJ (1993) Prolonges endurance exercise and blood coagulation: a 9 month prospective study. Blood Coagul Fibrinolysis 4: 21-25

51. Van Loon B-J P, Heere LP, Kluft C, Brïet E, Doijewaard G, Meinders AE (1992) Fibrinolytic system during long-distance running in IDDM patients and in healthy subjects. Diabetes Care 15: 991-995

52. Hornsby WG, Boggess KA, Lyons TJ, Barnwell WH, Lazarchick J, Colwell JA (1990) Hemostatic alterations with exercise conditioning in NIDDM. Diabetes Care 13: 87-92 